\title{
West Nile virus transmission: results from the integrated surveillance system in Italy, 2008 to 2015
}

C Rizzo ${ }^{1}$, C Napoli 1 , G Venturi ${ }^{1}$, S Pupella ${ }^{2}$, L Lombardini ${ }^{3}$, P Calistri 4 , F Monaco 4 , R Cagarelli 5 , P Angelini 5 , R Bellini 6 , M Tamba ${ }^{7}$, A Piatti ${ }^{8}$, F Russo ${ }^{9}, G$ Palù ${ }^{10}, M$ Chiari ${ }^{11}$, A Lavazza ${ }^{11}$, A Bella ${ }^{1}$, the Italian WNV surveillance working group ${ }^{12}$

1. National Institute of Health (Istituto Superiore di Sanità, ISS), Italy

2. National Blood Centre, National Institute of Health (Istituto Superiore di Sanità, ISS), Italy

3. National Transplant Centre, National Institute of Health (Istituto Superiore di Sanità, ISS), Italy

4. Istituto Zooprofilattico Sperimentale dell’Abruzzo e del Molise “G. Caporale”, Italy

5. Regional Health Authority of Emilia-Romagna, Italy

6. Centro Agricoltura Ambiente "G. Nicoli", Crevalcore, Italy

7. Istituto Zooprofilattico Sperimentale della Lombardia e dell’Emilia-Romagna, Brescia, Italy

8. Regional Health Authority of Lombardy, Italy

9. Regional Health Authority of Veneto, Italy

10. Department of Molecular Medicine, University of Padua, Padua, Italy

11. Istituto Zooprofilattico Sperimentale della Lombardia e dell’Emilia-Romagna 'Bruno Ubertini', Brescia, Italy

12. Members of the group are listed at the end of the article

Correspondence: Caterina Rizzo (caterina.rizzo@iss.it)

Citation style for this article:

Rizzo C, Napoli C, Venturi G, Pupella S, Lombardini L, Calistri P, Monaco F, Cagarelli R, Angelini P, Bellini R, Tamba M, Piatti A, Russo F, Palù G, Chiari M, Lavazza A, Bella A, the Italian WNV surveillance working group. West Nile virus transmission: results from the integrated surveillance system in Italy, 2008 to 2015 . Euro Surveill. 2016;21(37):pii=30340. DOI: http://dx.doi.org/10.2807/1560-7917.ES.2016.21.37.30340

Article submitted on 11 January 2016 / accepted on 17 June 2016 / published on 15 eptember 2016

In Italy a national Plan for the surveillance of imported and autochthonous human vector-borne diseases (chikungunya, dengue, Zika virus disease and West Nile virus (WNV) disease) that integrates human and veterinary (animals and vectors) surveillance, is issued and revised annually according with the observed epidemiological changes. Here we describe results of the WNV integrated veterinary and human surveillance systems in Italy from 2008 to 2015. A real time data exchange protocol is in place between the surveillance systems to rapidly identify occurrence of human and animal cases and to define and update the map of affected areas i.e. provinces during the vector activity period from June to October. WNV continues to cause severe illnesses in Italy during every transmission season, albeit cases are sporadic and the epidemiology varies by virus lineage and geographic area. The integration of surveillance activities and a multidisciplinary approach made it possible and have been fundamental in supporting implementation of and/or strengthening preventive measures aimed at reducing the risk of transmission of WNV trough blood, tissues and organ donation and to implementing further measures for vector control.

\section{Introduction}

West Nile virus (WNV), a single stranded RNA virus of the genus Flavivirus, is mostly transmitted by mosquito bites, but also through organ transplantation, blood transfusion, in the laboratory setting and from mother to child during pregnancy, delivery, or breastfeeding [1]. The virus is maintained in a continuous vertebrate-mosquito cycle. Mosquitoes are the vectors and birds are the reservoir for West Nile virus. Humans, horses and other mammals are considered dead-end hosts and do not contribute to further spread of the disease.

In humans, ca $80 \%$ of infections are asymptomatic, $20 \%$ of those infected may present with fever and or influenza-like symptoms, whereas less than $1 \%$ i.e. mostly the elderly and immunocompromised people, develop West Nile neuroinvasive diseases (WNND) such as encephalitis, meningo-encephalitis or meningitis that may lead to death $[1,2]$.

In 1996, the first large human outbreak of WND in Europe was reported in Romania with 393 confirmed cases [3] and since then, the number of WNND cases reported in humans increased significantly. From 2002 to 2009 , several WNV outbreaks were reported in a few European and neighbouring countries (Albania, Bosnia, Bulgaria, Croatia, FYROM, Greece, Hungary, Italy, Kosovo, Montenegro, Portugal, Romania, Russia, Serbia, Spain, Turkey, Ukraine) [4]. After 2005, an endemic transmission cycle started in some southeastern and eastern European countries with annual outbreaks [5-8], mostly sustained by the rapid spread of WNV lineage 2 strains belonging to the Hungarian and Volgograd clade [9].

In Italy, the first outbreak of WNV infection was reported in 1998 in the region of Tuscany [10] and since 2001, a national veterinary surveillance plan for WNV 


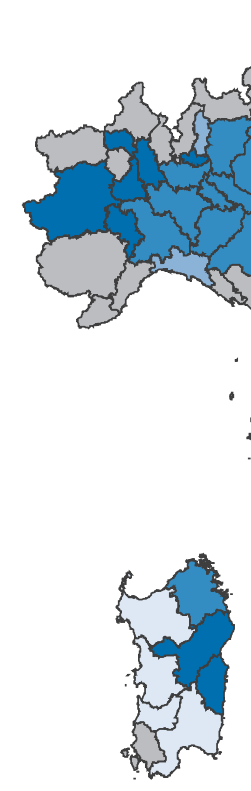

B. Human cases

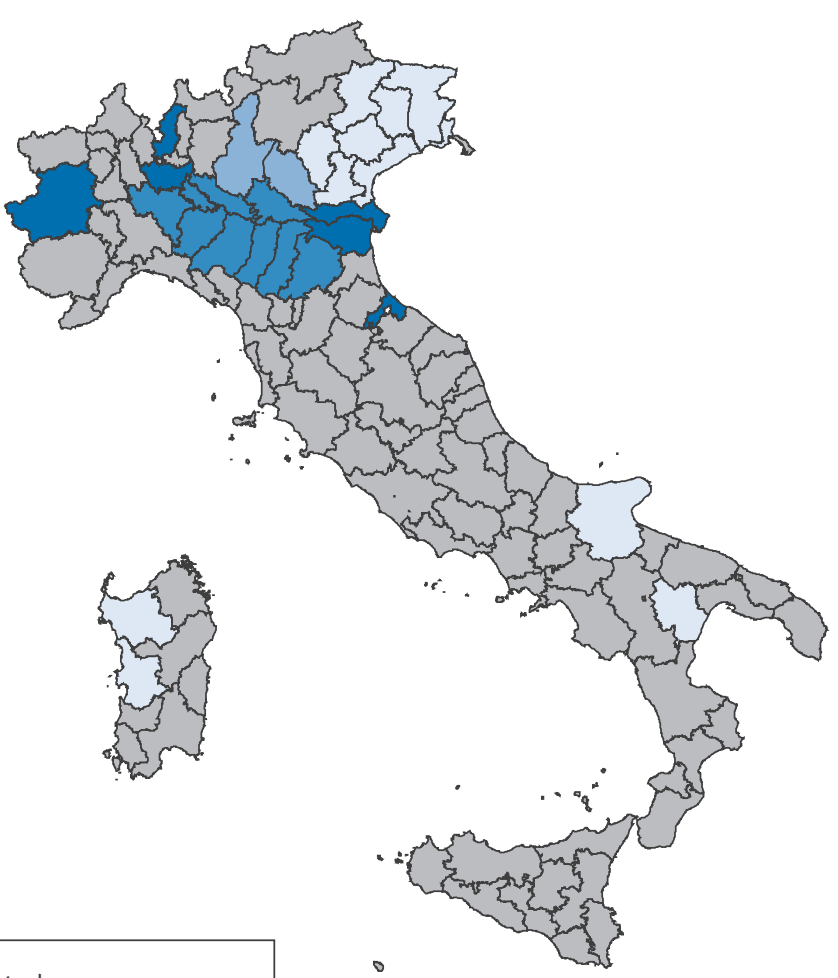

No reported cases

Earliest seasons (2008-2013)

2014 season

2014 and 2015 seasons

2015 season based on wild bird mortality and on entomological and sentinel animal surveillance has been in place. The plan aims at monitoring areas at risk for WNV circulation, and detecting WNV seroconversion in horses in these areas $[10,11]$. In parallel, in 2002, human surveillance recommendations were issued by the Ministry of Health requesting all 21 Italian regions and autonomous provinces and autonomous provinces to report to the national mandatory surveillance system all hospitalised cases of aseptic meningitis and encephalitis with unknown aetiology, and cases of fever with rash in the areas where veterinary cases where identified. Moreover, health authorities were requested to actively identify cases and possible WNV seroconversion in close contacts of infected animals such as employees of stables and veterinarians or people living in the area [12].

The veterinary and human surveillance systems did not detect any relevant circulation of WNV until 2008, when the virus was identified in mosquitoes, birds, horses and humans in the area surrounding the Po river delta, involving three north Italian regions [2].
Since the re-introduction of the virus in 2008 , a constant and intensified WNV circulation across the whole of Italy was observed with a geographical spread of WNV to the west and south $[2,13]$. Moreover, from 2008 to 2011, WNV lineage 1 was responsible for reported human WNDD cases, but, since 2011, evidence of extensive circulation of lineage 2 closely related to both the Hungarian and Volgograd clades, was demonstrated [13-15]. This suggests a possible introduction of lineage 2 from central and/or eastern European countries, probably through migratory birds $[16,17]$.

WNV has caused severe illnesses in humans in Italy every season over nearly a decade. However, cases occur sporadically and the epidemiology varies according to the virus lineage and the affected geographic area. Integrated surveillance is essential to identify outbreaks in a timely fashion and to guide prevention efforts aimed at reducing the incidence of severe cases and at reducing the probability of virus transmission via blood, tissue and organ donations. 


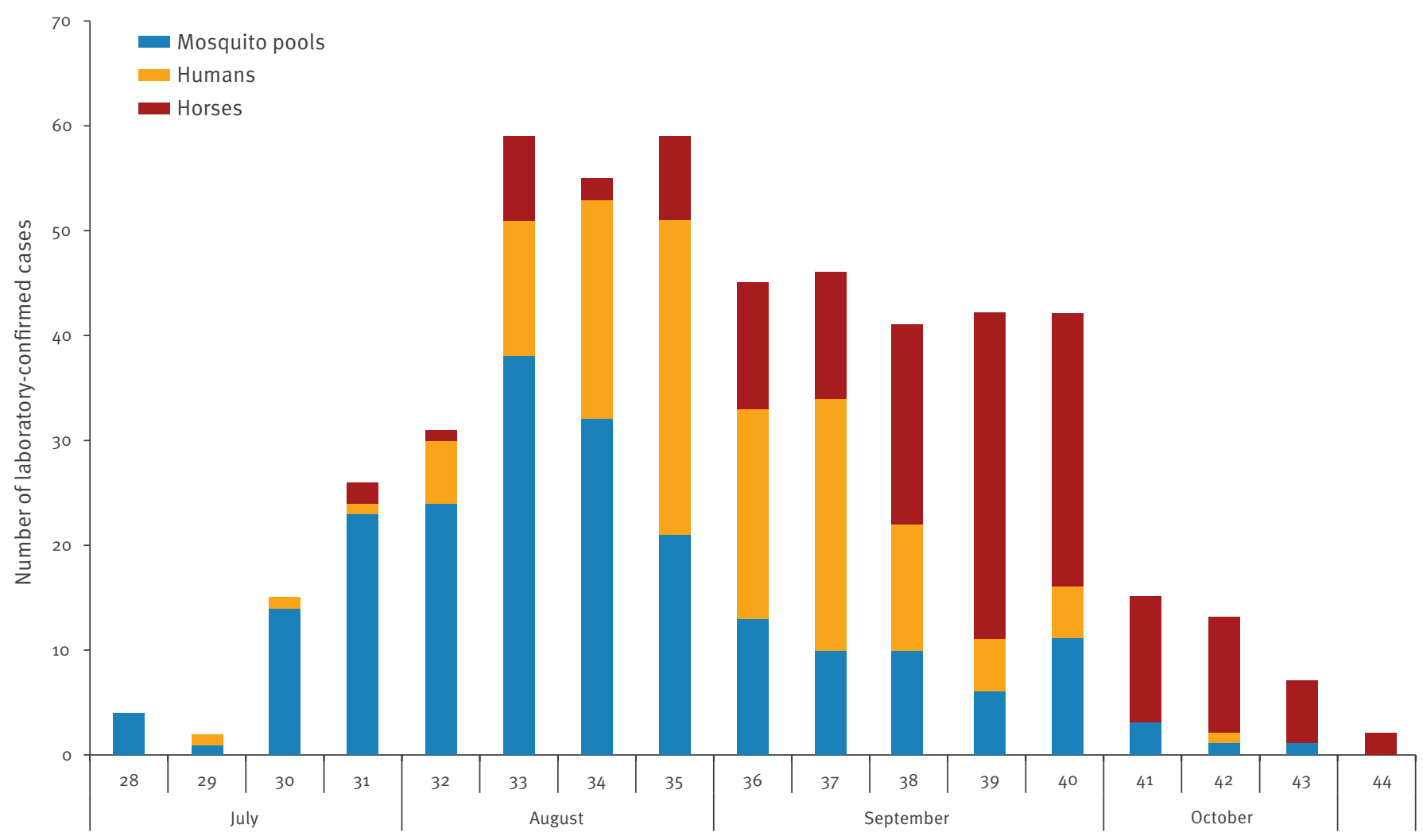

Month and calendar weeks

Here we present the evolution of the national surveillance plan in the five years following its first implementation, and briefly describe results of the WNV integrated surveillance system in Italy.

\section{Methods}

\section{The integrated veterinary and human} surveillance systems in Italy

In 2008 and 2011, the national WNV veterinary surveillance plan [18] and the WNND human surveillance recommendations [19] were revised, respectively. New activities were added including the potential integration between veterinary (animals and vectors) and human surveillance. Provinces with evidence of animal and vector or human infections in the previous season have to implement active surveillance and mandatory screening of blood donations. The veterinary and human plans have been published separately and they were revised annually according to the epidemiological situation in the country. Since 2009, some north Italian regions have implemented an integrated surveillance, targeting mosquitoes, birds, and humans [15].

Pillars of the national integrated surveillance system are (i) the entomological monitoring based on mosquito collections in selected sites; (ii) the animal surveillance targeting migratory and resident birds as well as horses and poultry; (iii) the human surveillance system requesting clinicians to report all possible, probable and confirmed WNV cases, irrespective of age, using a modified European case definition which includes neurological symptoms in the clinical criteria [2].

For veterinary surveillance purposes, the Italian territory was subdivided in two distinct epidemiological territories: endemic and non-endemic. The former includes the territories where WNV was detected in the previous two years. At present these are the plain of the Po river valley, including Friuli Venezia Giulia, Emilia Romagna, Lombardy, Piedmont, Veneto regions, and the two main Italian islands: Sardinia and Sicily. The remainder of Italy is considered non-endemic. In the endemic territories, an early warning system is in place, which enables the reinforcement of the activities aiming at detecting WNV in vectors and birds [20]. In particular, the regions of the plain of the Po river i.e. Friuli Venezia Giulia, Emilia Romagna, Lombardy, Piedmont, Veneto, operate an enhanced surveillance system based on a network of fixed mosquito traps (in grids from 10 to $20 \mathrm{~km}$ ) and on the collection of residential wild birds, mainly Corvidae. Timely data on viral circulation triggers preventive measures to avoid the virus transmission via blood, tissue and organ donations $[15,21,22]$. 


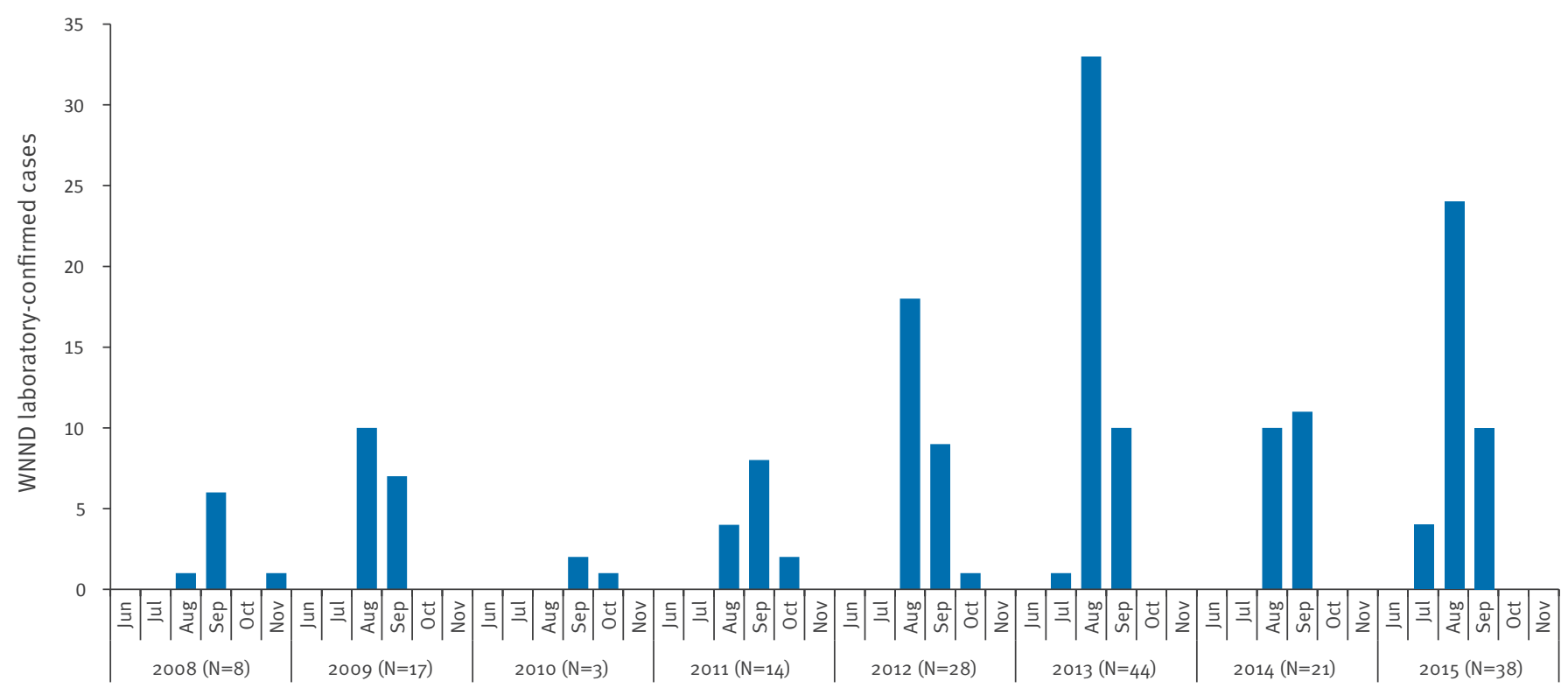

Year/Month onset

WNND: West Nile neuroinvasive diseases.

Data collected through the Veterinary Plan are registered using an information system (SISMAN) that records and manages laboratory results and publishes weekly and daily reports describing the outcomes of the surveillance activities. A web-based geographic information system (WebGIS) was developed for displaying thematic maps and to help the veterinary services to explore the area surrounding the outbreak, and to create buffers around the reported cases.

Human cases are notified by regional and local authorities to the Ministry of Health and to the Istituto Superiore di Sanità (ISS, national public health institute) using a specific password-protected web-based system, which permits to report probable and confirmed cases, adding available epidemiological (including the province of exposure), clinical and laboratory information. The web-based system is accessible also to the National Blood Center (NBC) and to the National Transplant Center (NTC), which implement precautionary measures on blood donation and transplant activities also on the basis of data on WNV human cases.

In order to rapidly identify, define and update the map of the affected areas i.e. provinces during the vector activity period, a real-time data exchange protocol is in place between the two systems.

\section{Definitions and identification of at risk areas in Italy}

The national plan for human surveillance defines as 'affected areas' all the provinces (Nomenclature of
Units for Territorial Statistics (NUTS)-3) [23] where laboratory-confirmed WNV infections in animals, vectors or humans, irrespective of age, were notified in the previous years or during the surveillance period. The 'surveillance period' covers the months between the 1 June and 30 October, which is considered the period with the highest vector activity. Identification of an affected area immediately triggers the definition of the 'surveillance area' for the whole region (NUTS-2 level) where the affected area is located. In the surveillance area, passive human surveillance has to be set up, and physicians are requested to report all possible, probable and confirmed WNND cases. In the affected areas, the NBC and the NTC immediately activate the WNV screening, by Nucleic Acid Amplification Test (NAT), of all blood, blood component, and organ donations until the end of the vector season in order to avoid WNV transmission [24].

\section{Data analysis}

In our analysis we included autochthonous confirmed cases of WNND, West Nile fever and infections detected in blood and in organ donors; we also analysed data on vectors and birds. Annual incidence rates in human in the period from 2008 to 2015 were calculated using annual resident province population. All population data were obtained from the Italian National Institute of Statistics (ISTAT) [8]. The statistical analysis was carried out using STATA software version 11.2 (Stata Corporation, College Station, TX, US). Maps were produced using Epi Info version 7 (CDC, Atlanta, GA, US). 
Veterinary surveillance for West Nile virus in birds, mosquitoes, horses and chickens, Italy by year, 2008-2015

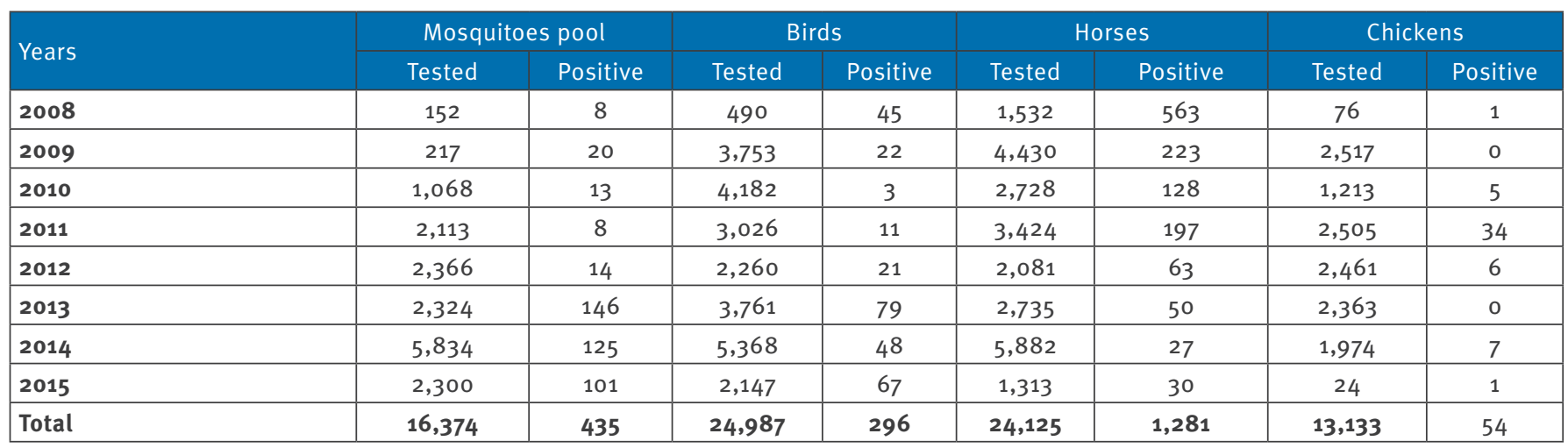

\section{Results}

In Italy from 2008 to 2015 , the circulation of WNV was reported in mosquitoes, birds and horses in the territory of 14 regions, with 173 indigenous cases of human WNND notified in eight regions (Apulia, Basilicata, Emilia-Romagna, Friuli Venezia Giulia, Lombardy, Piedmont, Sardinia, Veneto). Figure 1 shows the geographical distribution of human and equine neuroinvasive cases detected in Italy from 2008 to 2015.

Results of the veterinary surveillance from 2008 to 2015 are reported in Table 1 . Since 2008 , more than 16,000 mosquito pools have been tested, with 435 positive results, in eight regions and 30 provinces where subsequently human WNND cases were reported. Positive mosquito pools without consecutive or previous detection of WNND in humans were detected in 2008 in the province of Brescia, Lombardy region $(n=1)$; in 2011 in the province of Messina, Sicily region $(n=1)$ and in 2014 in the province of Genoa province, Liguria region and in the province of Alessandria province, Piedmont region $(n=2$, respectively).

In the provinces where there were also human cases, viral circulation in mosquitoes preceded human WNV (WNND and West Nile fever) cases with a mean of 22 days (range 0-58), except for few provinces (2011: $n=1$, 2012: $n=2,2013$ and 2015: $n=3$, respectively) where the identification of human cases anticipated the evidence of viral circulation in vectors (Figure 2).

Also from 2008 to 2015 , more than 24,000 residential birds were examined, with 296 positive results. WNV was found in birds in six regions. In the 15 provinces where there were human cases, positive birds were identified with a mean of 35 days (range 1-315 days) before the appearance of human cases.

During 2008 to 2010, all isolated viruses belonged to WNV-lineage 1, from 2011 to 2012 lineage 1 and 2 cocirculated with a higher proportion of lineage 1 and from 2013 to 2015 lineage 2 prevailed over lineage 1 with evidence of lineage 1 circulation only in one province each season.

\section{Human cases}

The national incidence of WNND peaked in $2013(1.66 / 1,000,0000$ inhabitants) and 2015 (1.34/1,000,0000). From 2008 to 2011, the annual incidence was relatively low (median: 0.41/1,000,000; range: 0.11-0.64). From 2012 to 2015, the national incidence of WNND increased by threefold (median: 1.20/1,000,0000; range: $0.78-1.66$ ). The increase in disease incidence was initially concentrated in northern Italy moving over time towards the south, mainly to areas in central and to some areas in southern Italy. However, 91\% (157/173) of the WNND cases detected during the entire study period were reported from three regions (Emilia-Romagna, Lombardy and Veneto) in the Po river plain area (Table 2) with the Emilia-Romagna and Veneto regions reporting the highest incidence (1.60 and $1.46 / 1,000,000$ respectively).

The distribution of human WNND cases by month and year of symptom onset is reported in Figure 3.

The median age of cases was 73 years (range: 10-90 years) during the entire surveillance period, varying from a minimum of 67 years (range: 41-68 years) in 2010 to 77 years (range: $42-89$ years) in 2013. Most of the reported cases $(69 \%, 120 / 173)$ were male. All WNND cases were hospitalised: 82 presented as encephalitis, 44 as meningo-encephalitis, 31 as meningitis, seven as polyradiculoneuritis, one as facial paralysis and eight as other neurological symptoms: meningeal symptoms $(n=2)$, extrapyramidal syndrome $(n=1)$, confusion $(n=1)$, headache $(n=1)$, ataxic paraparesis $(n=1)$, neuropathy of lower limbs $(n=1)$, symptoms were not specified for one case. Eighteen of the 173 WNND cases died (2009: $n=3 ; 2011: n=5 ; 2012: n=1 ; 2013: n=7 ; 2014$ and 2015: $\mathrm{n}=1$ each), corresponding to an overall case fatality rate of $10 \%$. The median age of WNND fatal cases was 82 years (range: $34-89$ years), 14 of 18 were male. All fatal cases were reported to have chronic conditions before symptom onset and 10 presented with encephalitis, six with meningo-encephalitis and two with meningitis.

In the entire period, 69 confirmed cases of WNV fever were reported to the national surveillance system from 
Incidence of human West Nile neuroinvasive disease cases per 1,000,000 inhabitants by province and year, Italy $2008-2015$ $(n=173)$

\begin{tabular}{|c|c|c|c|c|c|c|c|c|c|c|c|c|c|c|c|c|c|}
\hline \multirow{2}{*}{ Region } & \multirow{2}{*}{ Province } & \multicolumn{2}{|r|}{2008} & \multicolumn{2}{|r|}{2009} & \multicolumn{2}{|r|}{2010} & \multicolumn{2}{|r|}{2011} & \multicolumn{2}{|r|}{2012} & \multicolumn{2}{|r|}{2013} & \multicolumn{2}{|r|}{2014} & \multicolumn{2}{|r|}{2015} \\
\hline & & $N$. & Incidence & $N$. & Incidence & $N$. & Incidence & $N$ & Incidence & $N$. & Incidence & $N$. & Incidence & $N$. & Incidence & $N$. & Incidence \\
\hline Piedmont & Torino & 0 & NA & 0 & NA & 0 & NA & 0 & NA & 0 & NA & 0 & NA & 0 & NA & 1 & 0.44 \\
\hline \multirow{6}{*}{ Lombardy } & Brescia & 0 & NA & 0 & NA & 0 & NA & 0 & NA & 0 & NA & 2 & 1.60 & 1 & 0.79 & 0 & NA \\
\hline & Cremona & 0 & $N A$ & 0 & NA & 0 & $N A$ & 0 & NA & 0 & NA & 1 & 2.76 & 3 & 8.28 & 4 & 11.06 \\
\hline & Lodi & 0 & NA & 0 & NA & 0 & NA & 0 & NA & 0 & NA & 1 & 4.43 & 2 & 8.73 & 3 & 13.07 \\
\hline & Mantova & 0 & NA & 2 & 4.88 & 0 & NA & 0 & NA & 0 & NA & 6 & 14.59 & 2 & 4.82 & 3 & 7.23 \\
\hline & Milano & 0 & NA & 0 & NA & 0 & NA & 0 & NA & 0 & NA & 0 & NA & 0 & NA & 4 & 1.25 \\
\hline & Pavia & 0 & NA & 0 & NA & 0 & NA & 0 & NA & 0 & NA & 0 & NA & 5 & 9.12 & 5 & 9.11 \\
\hline \multirow{7}{*}{ Veneto } & Belluno & 0 & NA & 0 & NA & 0 & NA & 1 & 4.68 & 0 & NA & 0 & NA & 0 & NA & 0 & NA \\
\hline & Padova & 0 & $N A$ & 0 & NA & 0 & NA & 0 & NA & 0 & NA & 1 & 1.08 & 0 & NA & 0 & NA \\
\hline & Rovigo & 3 & 12.18 & 5 & 20.23 & 0 & NA & 0 & NA & 0 & NA & 5 & 20.61 & 0 & NA & 1 & 4.12 \\
\hline & Treviso & 0 & NA & 0 & NA & 0 & NA & 6 & 6.75 & 6 & 6.85 & 4 & 4.54 & 0 & NA & 0 & NA \\
\hline & Venezia & 1 & 1.18 & 1 & 1.17 & 2 & 2.33 & 1 & 1.16 & 15 & 17.72 & 2 & 2.36 & 0 & NA & 0 & NA \\
\hline & Verona & 0 & NA & 0 & NA & 0 & NA & 0 & NA & 0 & NA & 1 & 1.10 & 1 & 1.08 & 0 & NA \\
\hline & Vicenza & 1 & 1.17 & 0 & NA & 1 & 1.15 & 0 & NA & 0 & NA & 0 & NA & 0 & NA & 0 & NA \\
\hline \multirow{3}{*}{$\begin{array}{l}\text { Friuli } \\
\text { Venezia } \\
\text { Giulia }\end{array}$} & Gorizia & 0 & NA & 0 & NA & 0 & NA & 0 & NA & 1 & 7.15 & 0 & NA & 0 & NA & 0 & NA \\
\hline & Pordenone & 0 & NA & 0 & NA & 0 & NA & 0 & NA & 2 & 6.44 & 0 & NA & 0 & NA & 0 & NA \\
\hline & Udine & 0 & NA & 0 & NA & 0 & NA & 2 & 3.69 & 1 & 1.87 & 0 & NA & 0 & NA & 0 & NA \\
\hline \multirow{7}{*}{$\begin{array}{l}\text { Emilia- } \\
\text { Romagna }\end{array}$} & Bologna & 1 & 1.04 & 2 & 2.05 & 0 & NA & 0 & NA & 0 & NA & 1 & 1.01 & 1 & 1.00 & 2 & 1.99 \\
\hline & Ferrara & 2 & 5.62 & 5 & 13.97 & 0 & NA & 0 & NA & 0 & NA & 5 & 14.18 & 0 & NA & 1 & 2.82 \\
\hline & Modena & 0 & NA & 2 & 2.91 & 0 & $N A$ & 0 & NA & 0 & NA & 7 & 10.17 & 2 & 2.85 & 8 & 11.39 \\
\hline & Parma & 0 & NA & 0 & NA & 0 & NA & 0 & NA & 0 & NA & 1 & 2.32 & 1 & 2.26 & 3 & 6.74 \\
\hline & Piacenza & 0 & NA & 0 & NA & 0 & NA & 0 & NA & 0 & NA & 0 & NA & 2 & 6.93 & 1 & 3.47 \\
\hline & $\begin{array}{c}\text { Reggio } \\
\text { nell'Emilia }\end{array}$ & 0 & NA & 0 & NA & 0 & NA & 0 & NA & 0 & NA & 6 & 11.48 & 1 & 1.87 & 1 & 1.88 \\
\hline & Rimini & 0 & NA & 0 & NA & 0 & NA & 0 & NA & 0 & NA & 0 & NA & 0 & NA & 1 & 2.98 \\
\hline Apulia & Foggia & 0 & NA & 0 & NA & 0 & NA & 0 & NA & 0 & NA & 1 & 1.59 & 0 & NA & 0 & NA \\
\hline Basilicata & Matera & 0 & NA & 0 & NA & 0 & NA & 0 & NA & 1 & 5.00 & 0 & NA & 0 & NA & 0 & NA \\
\hline \multirow{2}{*}{ Sardinia } & Oristano & 0 & NA & 0 & NA & 0 & NA & 3 & 18.05 & 2 & 12.22 & 0 & NA & 0 & NA & 0 & NA \\
\hline & Sassari & 0 & NA & 0 & NA & 0 & NA & 1 & 2.97 & 0 & NA & 0 & NA & 0 & NA & 0 & NA \\
\hline
\end{tabular}

NA: not applicable.

four Italian regions (Emilia-Romagna $n=31$, Lombardy $n=3$, Marche $n=1$, and Veneto $n=34$ ).

\section{Situation in 2015}

In Italy in 2015 , since the beginning of the surveillance period, for the first time since 2008 , four cases, two from Emilia-Romagna and Lombardy region, respectively, all had symptom onset in the last week of July (calendar week 31). The last human cases reported had onset of symptoms or were detected in mid-September and the integrated surveillance detected signals of WNV circulation (veterinary cases), for the first time ever, in a northern-western region (Piedmont), where also one WNND case was reported. Moreover, virus circulation was detected in animals for the first time in the southern Italian regions Apulia (1 horse) and Sicily (1 chicken), where no human cases were reported.

In 2015 , a total of 316,614 WNV NAT screening tests were conducted in blood donors in the affected provinces and 13 asymptomatic donors, six in Emilia Romagna and seven in Lombardy were identified. No donor or organ transplant recipients were positive for WNV among the 168 tested.

\section{Discussion and conclusions}

In Italy from 2008 to 2015, the circulation of WNV was reported in mosquitoes, birds and horses in the territory of 14 regions [10], with 173 auchtotonous cases of human WNND notified. [11]. A peak of cases was reported in 2013, a second peak was observed in 2015. From 2008 to 2015, the Italian contribution to the European case load increased substantially i.e. from a minimum of $11 \%(14 / 128)$ in 2011 to a maximum of $56 \%(60 / 108)$ in $2015[3,9]$. Moreover, in this period, an expansion of the Italian affected areas from the northeast to the north-west and south was observed.

From 2008 to 2010, only circulation of lineage 1 was reported. The complexity of the epidemiological scenario increased in 2011 with the detection of the novel lineage 2 which overcame lineage 1 from 2013 to 2015 and was responsible for both human and animal cases [12]. It is not clear why there was more WNV activity 
in the past 4 years of surveillance (2012-2015) compared to the earlier surveillance period (2008-2011). However, virus lineage and virulence, weather conditions, bird population size and immunity, vector density, and human behaviour, are all factors that play a role in determining if, when and where human outbreaks may occur.

In Europe, since 2008, WNV has spread into areas not previously affected, including Greece [25], Portugal [26], Turkey [27], and many eastern European countries (Albania, Bosnia and Herzegovina, Bulgaria, Croatia, the former Yugoslav Republic of Macedonia, Kosovo under UN Security Council Resolution 1244, Montenegro, Serbia) [28-30]. In the same period the disease has been reported in Hungary, Israel, Italy, Romania, Russia, Spain and Ukraine $[2,29]$.

The fact that the WNV has become endemic in Italy has brought the local and national Italian authorities to strengthen the WNV surveillance system and for this reason, probably, Italy is the country with the highest number of reported cases in EU, while other EU countries have different epidemiological situations, with different surveillance systems and objectives [31].

Surveillance of WNV circulation requires an interdisciplinary approach given the complexity of the viral biological cycle. For this reason, the integration of entomological, veterinary and human surveillance systems is an essential tool for public health. In fact, the veterinary and entomological surveillance activities are crucial for estimating the public health risk associated with WNV, and for the effective and timely control of the disease in humans. In Italy, a serious effort has been made to strengthen the integration of human with veterinary and entomological surveillance, reaching tangible results in the prevention of the disease $[3,7]$. In addition, since 2014 , some Italian regions have explored the feasibility of using vector and animal surveillance data to trigger blood and organ donor safety measures. Encouraging results were obtained in 2014, during a season with high level of transmission. In 2015 however, veterinary surveillance did not signal WNV circulation before the occurrence of human cases in all affected provinces. Still, when province borders are not taken strictly into account and the surrounding territories are considered, the entomological and veterinary surveillance was able to detect the virus circulation also in 2015. Veterinary surveillance identified WNV circulation in some regions (Apulia, Sardinia, Sicily) without any human cases. This could be related both to the under ascertainment or under notification of human cases to the surveillance system or to limited circulation of the virus between bird and mosquito populations in rural areas.

In conclusion, an integrated human, animal and vector surveillance is crucial to timely set up preventive measures, such as the early detection of infected blood donors.
The integration of surveillance activities and the multidisciplinary approach in Italy might be a good practice to be implemented also in other affected countries for the identification of viral circulation. They have been fundamental to implement and/or strengthen preventive measures aimed at reducing the risk of transmission of the WNV to humans.

The work that Italy has being doing in the past 8 years of surveillance is constantly enriched by an intense research activity and also by the development of innovative tools for the quantification of health risk in order to implement prevention measures and effective control.

Members of the WNV surveillance working group

Francesco Maraglino, Patrizia Parodi, Corrado Cenci (Ministry of Health, Italy); Nanni Costa (National Transplant Centre, Istituto Superiore di Sanità, ISS, Italy; Giancarlo Maria Liumbruno (National Blood Centre, National Institute of Health (Istituto Superiore di Sanità, ISS, Italy); Patrizio Pezzotti, Claudia Fortuna, Cristiano Fiorentini, Maria Elena Remoli, Eleonora Benedetti, Daniela Boccolini, Marco Di Luca, Roberto Romi, Francesco Severini, Luciano Toma, Luca Busani, Silvia Declich, Gianni Rezza (Istituto Superiore di Sanità, Rome Italy); Maria Paola Landini (Regional Reference Laboratory, Emilia-Romagna); Emanuela Bedeschi, Michele Dottori, Claudio Gualanduzzi, Annalisa Lombardini, Andrea Mattivi, Silvano Natalini, Gabriele Squintani, (EmiliaRomagna Region working group for WNV surveillance); Mariarita Gismondo, Francesca Rovida, Nadia Zanchetta, Davide Rossi and Fausto Baldanti (Regional Reference Laboratories, Lombardy Region, Italy); Maria Gramegna, Marco Farioli (Regional Health Authority of Lombardy, Italy); Davide Lelli, Alice Prosperi e Francesca Faccin (Istituto Zooprofilattico Sperimentale della Lombardia e dell'EmiliaRomagna 'Bruno Ubertini', Brescia, Italy); Francesca Zanella (Regional Health Authority of Veneto, Italy).

\section{Acknowledgements}

The authors would like to thank all health professionals from local and regional health authorities for collaborating. The project was implemented with a financial support of the Italian Ministry of Health-CCM.

\section{Conflict of interest}

None declared

\section{Authors' contributions}

$C R, C N, A B$, coordinated the human surveillance for WNV infections at national level, GV coordinated the activities of the national reference laboratory for WNV; SP coordinated the surveillance for WNV in blood donors, LL coordinated the surveillance for WNV in organ donors, PC and FM coordinated the veterinary surveillance of WNV; RC, PA, RB, MT, $A P, F R, G P, M C, A L$ coordinated the surveillance activities for WNV infections at regional level; $C R, C N, A B$ analysed the data and wrote the manuscript. All authors contributed to the discussion and reviewed the manuscript. All authors saw, commented upon and approved the final version of the paper. 


\section{References}

1. Colpitts TM, Conway MJ, Montgomery RR, Fikrig E. West Nile Virus: biology, transmission, and human infection.Clin Microbiol Rev. 2012;25(4):635-48. DOI: 10.1128/CMR.00045-12 PMID: 23034323

2. Rizzo C, Salcuni P, Nicoletti L, Ciufolini MG, Russo F, Masala R, et al. Epidemiological surveillance of West Nile neuroinvasive diseases in Italy, 2008 to 2011. Euro Surveill. 2012;17(20):20172.PMID: 22642945

3. Tsai TF, Popovici F, Cernescu C, Campbell GL, Nedelcu NI. West Nile encephalitis epidemic in southeastern Romania.Lancet. 1998;352(9130):767-71. DOI: 10.1016/S0140-6736(98)03538-7 PMID: 9737281

4. Conte A, Candeloro L, Ippoliti C, Monaco F, De Massis F, Bruno $\mathrm{R}$, et al. Spatio-Temporal Identification of Areas Suitable for West Nile Disease in the Mediterranean Basin and Central Europe. PLoS One. 2015;10(12):e0146024. doi: DOI: 10.1371/ journal.pone.0146024 . eCollection 2015. PMID: 26717483.

5. Tran A, Sudre B, Paz S, Rossi M, Desbrosse A, Chevalier V, et al. Environmental predictors of West Nile fever risk in Europe. Int J Health Geogr. 2014;13(1):26. DOI: 10.1186/1476-072X-1326 PMID: 24986363

6. European Centre for Disease Prevention and Control (ECDC). West Nile fever maps. [Accessed 27 Sep 2012]. Available from: http://ecdc.europa.eu/en/healthtopics/west_nile_fever/WestNile-fever-maps/pages/index.aspx

7. Rizzo C, Vescio F, Declich S, Finarelli AC, Macini P, Mattivi A, et al. West Nile virus transmission with human cases in Italy, August - September 2009. Euro Surveill. 2009;14(40):19353. PMID: 19822123

8. European Centre for Disease Prevention and Control (ECDC). Epidemiological situation of West Nile virus infection in the European Union. 13 July 2012. Available from: http://ecdc. europa.eu/en/publications/publications/1207-ter-rapid-riskassessment-west-nile-virus.pdf

9. Rizzoli A, Jimenez-Clavero MA, Barzon L, Cordioli P, Figuerola J, Koraka P, et al. The challenge of West Nile virus in Europe: knowledge gaps and research priorities. Euro Surveill. 2015;20(20):21135. DOI: 10.2807/1560-7917. ES2015.20.20.21135 PMID: 26027485

10. Autorino GL, Battisti A, Deubel V, Ferrari G, Forletta R, Giovannini A, et al. West Nile virus epidemic in horses, Tuscany region, Italy. Emerg Infect Dis. 2002;8(12):1372-8. DOI: 10.3201/eido812.020234 PMID: 12498650

11. Calistri P, Monaco F, Savini G, Guercio A, Purpari G, Vicari $D$, et al. Further spread of West Nile virus in Italy. Vet Ital. 2010;46(4):467-74.PMID: 21120802

12. Ministero della Salute. Circolare n. 400.3/3.2/ 4234 Sorveglianza delle infezioni da virus West Nile in Italia. www. pippo.it 2002.

13. Magurano F, Remoli ME, Baggieri M, Fortuna C, Marchi A, Fiorentini $C$, et al. Circulation of West Nile virus lineage 1 and 2 during an outbreak in Italy. Clin Microbiol Infect. 2012;18(12): E545-7. DOI: 10.1111/1469-0691.12018 PMID: 23020657

14. Bagnarelli P, Marinelli K, Trotta D, Monachetti A, Tavio M, Del Gobbo R, et al. Human case of autochthonous West Nile virus lineage 2 infection in Italy, September 2011. Euro Surveill. 2011:16(43):20002.PMID: 22085600

15. Calzolari M, Pautasso A, Montarsi F, Albieri A, Bellini R, Bonilauri P, et al. West Nile Virus Surveillance in 2013 via Mosquito Screening in Northern Italy and the Influence of Weather on Virus Circulation. PLoS One. 2015;10(10):e0140915. DOI: 10.1371/journal.pone.0140915 PMID: 26488475

16. Ravagnan S, Montarsi F, Cazzin S, Porcellato E, Russo F, Palei $M$, et al. First report outside Eastern Europe of West Nile virus lineage 2 related to the Volgograd 2007 strain, northeastern Italy, 2014. Parasit Vectors. 2015;8(1):418. DOI: 10.1186/ S13071-015-1031-y PMID: 26265490

17. Barzon L, Papa A, Lavezzo E, Franchin E, Pacenti M, Sinigaglia $A$, et al. Phylogenetic characterization of Central/Southern European lineage 2 West Nile virus: analysis of human outbreaks in Italy and Greece, 2013-2014. Clin Microbiol Infect. 2015;21(12):1122.e1-10. DOI: 10.1016/j.cmi.2015.07.018 PMID: 26235197

18. Ministero della Salute. [Italian Ministry of Health.] Piano di sorveglianza nazionale per la encefalomielite di tipo West Nile (West Nile Disease). [National veterinary surveillance plan for West Nile encephalomyelitis (West Nile Disease).] (G.U. Serie Generale n. 36 del 12 febbraio 2008). Available from: http:// www.trovanorme.salute.gov.it/norme/dettaglioAtto?id=25243

19. Ministero della Salute. [Italian Ministry of Health.]

Sorveglianza della Malattia di West Nile in Italia, 2010.

[Surveillance of West Nile Disease in humans in Italy, 2010.]
Available from: http://www.normativasanitaria.it/normsanpdf/0000/34923_1.pdf

20. Napoli C, Iannetti S, Rizzo C, Bella A, Di Sabatino D, Bruno R, et al. Vector borne infections in Italy: results of the integrated surveillance system for West Nile disease in 2013. Biomed Res Int. 2015;2015:643439.

21. Gobbi F, Barzon L, Capelli G, Angheben A, Pacenti M, Napoletano G, et al. , Veneto Summer Fever Study Group. Surveillance for West Nile, dengue, and chikungunya virus infections, Veneto Region, Italy, 2010.Emerg Infect Dis. 2012;18(4):671-3. DOI: 10.3201/eid1804.110753 PMID: 22469230

22. Chiari M, Prosperi A, Faccin F, Avisani D, Cerioli M, Zanoni M, et al. West Nile Virus Surveillance in the Lombardy Region, Northern Italy. Transbound Emerg Dis. 2015;62(4):343-9. DOI: 10.1111/tbed.12375 PMID: 25958924

23. Italian National Institute of Statistics. Statistical codes of territorial administrative units. [Internet]. [Accessed 2016 Sept 08]. Available from: http://www.istat.it/it/archivio/6789

24. Pupella S, Pisani G, Cristiano K, Catalano L, Grazzini G. West Nile virus in the transfusion setting with a special focus on Italian preventive measures adopted in 2008-2012 and their impact on blood safety.Blood Transfus. 2013;11(4):563-74. PMID: 24120610

25. Papa A, Danis K, Baka A, Bakas A, Dougas G, Lytras T, et al. Ongoing outbreak of West Nile virus infections in humans in Greece, July-August 2010. Euro Surveill. 2010;15(34):15(34) pii:19644.PMID: 20807489

26. The World Organisation for Animal Health (OIE). World Animal Health Information Database (WAHID) Interface. Available from: http://www.oie.int/wahis_2/public/wahid.php/ Wahidhome/Home

27. Kalaycioglu H, Korukluoglu G, Ozkul A, Oncul O, Tosun $\mathrm{S}$, Karabay $\mathrm{O}$, et al. Emergence of West Nile virus infections in humans in Turkey, 2010 to 2011 . Euro Surveill. 2012;17(21):20182.PMID: 22687827

28. Sambri V, Capobianchi M, Charrel R, Fyodorova M, Gaibani $P$, Gould E, et al. West Nile virus in Europe: emergence, epidemiology, diagnosis, treatment, and prevention. Clin Microbiol Infect. 2013;19(8):699-704. DOI: 10.1111/14690691.12211 PMID: 23594175

29. European Center for Disease Prevention and Control (ECDC). Historical data. 2014. [Accessed 8 Sep 2016]. Available from: http://ecdc.europa.eu/en/healthtopics/west_nile_fever/westnile-fever-maps/pages/historical-data.aspx

30. Giese C, Aït El Belghiti F, Barboza P, Dente M, Fabiani M, Declich $S$, et al. West Nile virus circulation in the EpiSouth countries and neighbouring areas. Seasons 2010, 2011 and 2012. [Accessed 8 Sep 2016]. Available from: http://www. episouthnetwork.org/sites/default/files/outputs/note_west nile_episouth_2010_2011_2012__june2013.pdf

31. European Centre for Disease Prevention and Control (ECDC). Annual Epidemiological Report 2016 - West Nile fever. Stockholm: ECDC; 2016. [Accessed 8 Sep 2016]. Available from: http://ecdc.europa.eu/en/healthtopics/west_nile_fever/ Pages/Annual-epidemiological-report-2016.aspx

\section{License and copyright}

This is an open-access article distributed under the terms of the Creative Commons Attribution (CC BY 4.0) Licence. You may share and adapt the material, but must give appropriate credit to the source, provide a link to the licence, and indicate if changes were made.

This article is copyright of the authors, 2016. 